\title{
Simulation of cement-improved clay structures with a bonded elasto-plastic model: A practical approach
}

\author{
Marcos Arroyo ${ }^{\mathrm{a}, *}$, Matteo Ciantia ${ }^{\mathrm{b}}$, Riccardo Castellanza ${ }^{\mathrm{b}}$, Antonio Gens ${ }^{\mathrm{a}}$, Roberto Nova ${ }^{\mathrm{b}}$ \\ a Department of Geotechnical Engineering and Geosciences, UPC, Barcelona, Spain \\ ${ }^{\mathrm{b}}$ Dipartimento di Ingegneria Strutturale, Politecnico di Milano, Italy
}

\section{A R T I C L E I N F O}

\section{Article history:}

Received 4 December 2011

Received in revised form 10 May 2012

Accepted 10 May 2012

Available online 26 June 2012

\section{Keywords:}

Soil improvement

Numerical modelling

Constitutive relation

Clay

Cement

Cemented soils

Constitutive models

Calibration

Initialization

Excavation

\begin{abstract}
A B S T R A C T
Engineering practice has usually dealt with the treated soil bodies using simplistic constitutive models (e.g. elastic perfectly-plastic Mohr-Coulomb). In this paper, a more refined bonded elasto-plastic model is here applied, with emphasis on the ease of calibration. Empirical studies have identified the ratio of cement content to the cured mixture void ratio as a controlling variable for mechanical response. This observation is elaborated upon to show that measuring porosity and unconfined compressive strength is enough to initialize the state variables of a bonded elasto-plastic model. Data from cement-improved Bangkok clay is employed to illustrate and validate the calibration procedure proposed. The structurescale consequences of the constitutive model choice for the soil-cement are explored through the parametric analysis of an idealized excavation problem. A treated soil-cement slab is characterized by increasing cement contents in the clay-cement mixture. Two sets of parametric analysis are run characterizing the clay-cement either with a linear elastic-perfectly plastic model or with the bonded elasto-plastic model. The same values of unconfined compressions strength (UCS) are specified for the two models to make comparisons meaningful. Results from both series of analysis are compared highlighting the differences in predicted behaviour of the retaining wall and the excavation stability.
\end{abstract}

(ㄷ) 2012 Published by Elsevier Ltd.

\section{Introduction}

A number of soil improvement techniques result in soft clays mixed "in situ" with cement. While other aims might be also important (e.g. impermeabilization), frequently the prime role of the treated soil bodies is structural. This is the case, for instance of the soil-cement slabs often employed in deep excavations in soft soils to reduce wall displacements and/or impermeabilize the excavation bottom $[11,32]$. The slab has a structural role and its geometry and resistance need to be specified. While some simple design rules are available [18,32] a more in-depth analysis is sometimes necessary. A numerical simulation might be employed for the purpose, particularly if the movement of the retaining wall is required for design. The mechanical behaviour of the treated soil bodies is generally represented with simple models, typically the elastic perfectly plastic Mohr Coulomb model e.g. [15,25]. One characteristic that is poorly represented by that type of models is brittleness of mechanical response, a basic trait of cemented geomaterials both natural and artificial.

\footnotetext{
* Corresponding author.

E-mail address: marcos.arroyo@upc.edu (M. Arroyo).
}

On the other hand, brittleness is well captured by elasto-plastic bonded soil models [12]. Bonded soil models have already shown their value with very diverse natural materials, from soft rocks like calcarenite [20] to very soft Holocene structured clays [29,1]. Despite some early examples [10], the application of bonded soil models to cement-improved soils has received somewhat less attention until recently $[9,16]$.

One important obstacle to the practical application of bonded soil models is that they appear hard to calibrate. Nevertheless it is shown here that measuring porosity and unconfined compressive strength of the soil-cement and having knowledge of the amount of cement in the mixture is enough to initialize the main state variables of a bonded elasto-plastic model. Most of the other model parameters can be obtained from reconstituted samples of the treated soil.

A finite element model of a deep underwater excavation in clay partially sustained with a soil-cement slab is here employed as a trial case to study the influence in the excavation response of model-ling the slab with a simple or a more refined constitutive model. The same measured properties of the slab are always assumed (unconfined compressive strength, porosity, cement content), but they are interpreted differently to initialize the different constitutive models being compared. We thus explore if the micro brittle 
response of the bonded model at the small scale has consequences at the engineering scale.

\section{A constitutive model for bonded clays}

The bonded elasto-plastic model here employed is based on the CASM (Clay and Sand Model) developed by Yu [34] and is fully described by Gonzalez [14]. CASM is a versatile elasto-plastic hardening model that incorporates concepts such as critical state and the state parameter approach, and that, by a suitable selection of parameters, allows modelling of both sand and clay within a unified formulation. However, in common with other single yield surface models, CASM has some limitations and, for instance, is not suitable for cyclic loading, where models based on kinematic hardening formulations e.g. [29] would be more appropriate.

The original CASM has been here both extended, (by introducing a new scalar history variable, $b$, representing "bonding") and modified (by using a different plastic potential formulation from that originally proposed). The bonding variable enters the model following closely the original proposal of Gens and Nova [12]. The yield surface is assumed to enlarge with increasing amount of bonding in the soil. The reference material behaviour (unbonded) is recovered when $b$ goes to zero.

Fig. 1 shows the normal consolidation lines (NCL) and yield surfaces for both unbonded and bonded materials. The NCL for the reference material is given by $\lambda$ and $N$, two material parameters representing its slope and its volume at unit pressure, respectively. The slope of unloading-reloading lines for the unbounded clay, $\kappa$, is another material parameter. The yield surface can be expressed as follows:

$f=\left(\frac{q}{M_{\theta}\left(p^{\prime}+p_{t}^{\prime}\right)}\right)^{n}+\frac{1}{\ln r} \ln \frac{\left(p^{\prime}+p_{t}^{\prime}\right)}{p_{t}^{\prime}+p_{c}^{\prime}}=0$

Where, as in the following, all stresses are assumed effective. To obtain the behaviour shown in Fig. 1,

$p_{c}^{\prime}=p_{s}^{\prime}(1+b)$
$p_{t}^{\prime}=p_{s}^{\prime}\left(\alpha_{t} b\right)$
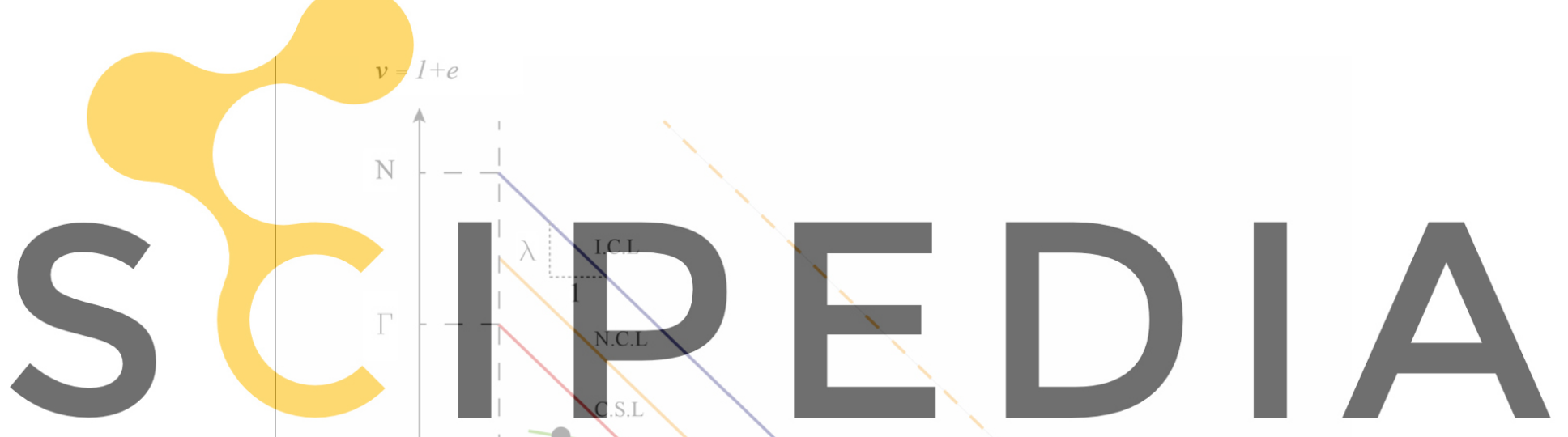

Register for free at https//www.scipédia.com to download the version without the watermark
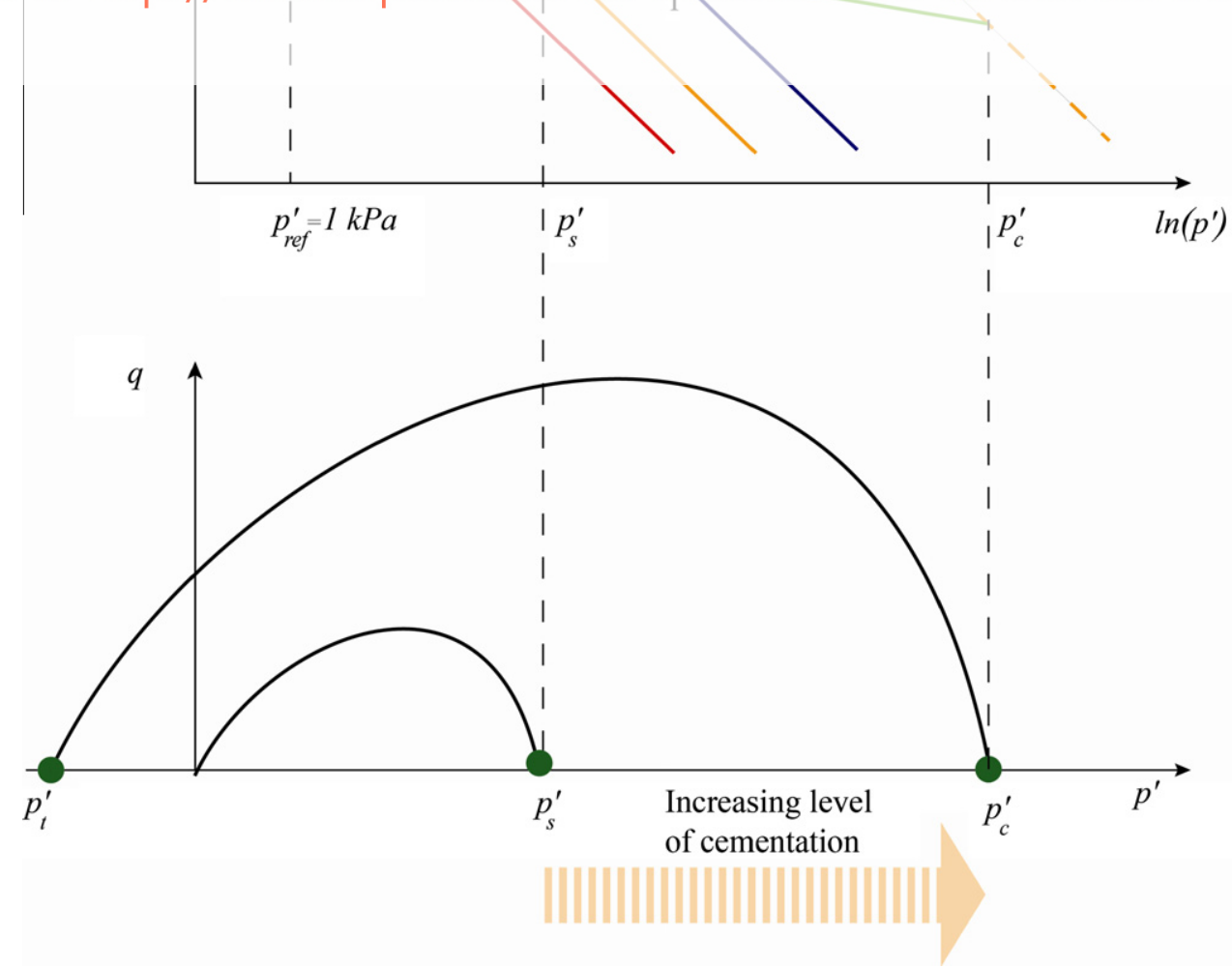

Fig. 1. Normal consolidation lines (NCL), critical state lines (CSL) and yield surfaces for both unbonded and bonded materials. 
$p_{c}^{\prime}$ controls the yielding of the bonded soil in isotropic compression and $p_{t}^{\prime}$ the cohesion and tensile strength of the material; $\alpha_{t}$ is a material parameter. $p_{s}^{\prime}$ is the equivalent preconsolidation pressure, or preconsolidation pressure of the unbonded reference material. This can be easily related (Fig. 1) to the relevant values of void ratio $e_{0 t}$ and mean stress $p_{0 t}^{\prime}$ as:

$p_{s}^{\prime}=\exp \left(\frac{N-\left(1+e_{0 t}\right)-\kappa \ln \left(p_{0 t}^{\prime}\right)}{\lambda-\kappa}\right)$

The parameters $n$ and $r$, inherited from CASM, control the shape of the yield surface. $M_{\theta}$ is a function of Lode's angle $\theta$ proposed by Sheng et al. [30], establishing the shape of the failure surface in the deviatoric plane. The plastic potential function, $g$, has a similar form to the yield surface. One extra adjustment parameter, $m$, is introduced to allow the possibility of non-associated behaviour:

$g=\left(\frac{m q}{M_{\theta}\left(p^{\prime}+p_{t}^{\prime}\right)}\right)^{n}+\frac{1}{\ln r} \ln \frac{\left(p^{\prime}+p_{t}^{\prime}\right)}{p_{t}^{\prime}+p_{c}^{\prime}}=0$

A classic volumetric hardening law is here employed for the unbonded material.

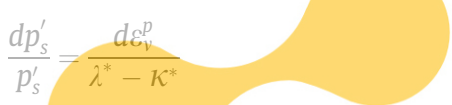

where $\lambda^{*}=\lambda /(1+e)$ and $\kappa^{*}=\kappa /(1+e)$. Since $p_{s}^{\prime}$ is a state variable that evolves only with plastic strain, its initial value for an artificially cemented clay is given by ( 3$)$ using the conditions $\left(e_{0 t}, p_{0 t}^{\prime}\right)$ operating when cementation took place. This initial value remains unaltered until the first plastic yield occurs.

Bonding $(b)$ decreases exponentially

age-measure $(h)$ :

$b=b$

$h_{1}$

$+h_{2}\left|\mathrm{~d} \varepsilon_{s}^{p}\right|$
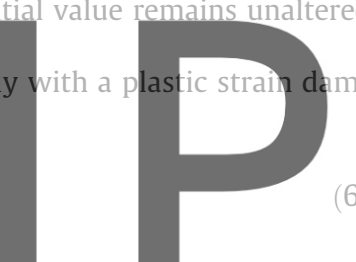

$h_{1}$ and $h_{2}$ are material parameters (greater than zero) defining the degradation rate. The parameters and state variables required by

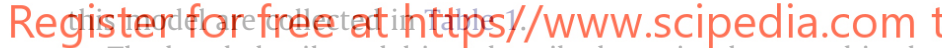
The bonded soil model just described was implemented in the finite element code PLAXIS, which has a facility to implement user-defined (UD) soil modeis [5]. The model vas implemented using an explicit integration algorithm with automatic substepping and error control techniques [31]. Further details can be found in Gonzalez [14].

Despite several examples of good performance (Gonzalez et al., 2007) [13] the model has some shortcomings. A significant one is that the elastic parameters $(\kappa, v)$ are independent of bonding. Yu et al. [35] propose a formulation where the elastic bulk modulus is made dependent on bonding. With the notation employed here, it reads

$K_{c}=\frac{(1+e) p^{\prime}}{\kappa}\left(1+\sqrt{\frac{p_{s}^{\prime} b}{p^{\prime}}}\right)$

Table 1

State variables and parameters of the cemented CASM model and calibrated values for the Bangkok clay case.

\begin{tabular}{|c|c|c|c|c|c|c|c|c|c|c|c|c|c|}
\hline \multicolumn{3}{|c|}{$\begin{array}{l}\text { State } \\
\text { variables }\end{array}$} & \multicolumn{11}{|c|}{ Parameters } \\
\hline \multirow[b]{2}{*}{$\sigma_{0}$} & \multirow[b]{2}{*}{$p_{s}$} & \multirow[b]{2}{*}{$b$} & \multicolumn{3}{|c|}{$\begin{array}{l}\text { Bonding } \\
\text { related }\end{array}$} & \multicolumn{8}{|c|}{ Reference material (reconstituted clay) } \\
\hline & & & $h_{1}$ & $h_{2}$ & $\alpha_{t}$ & $M$ & $\lambda$ & $N$ & $r$ & $n$ & $\kappa$ & $v$ & $m$ \\
\hline a & $\mathrm{a}$ & a & a & a & 0.5 & 1.2 & 0.282 & 4 & 1.25 & 3 & 0.03 & 0.2 & 3.7 \\
\hline
\end{tabular}

a See text.
Following this suggestion, it has been recently shown by Rios [28] that, for monotonic paths, the pre-yield performance of the CASM-bonded model can be significantly improved if the reloading line slope is chosen according to the following rule,

$\frac{1}{\kappa_{c}}=\frac{1}{\kappa}\left(1+\sqrt{\frac{p_{s}^{\prime} b}{p^{\prime}}}\right)$

where $\kappa_{c}$ is the value corresponding for a cemented material and all the state variables $\left(p^{\prime}, b, p_{s}^{\prime}\right)$ take their values. As shown in Section 4 , this rule has also proved useful here.

\section{Empirical observations on cemented Bangkok clay}

Cement-mixed Bangkok clay has benefited from a large experimental work by Bergado and co-authors [21,17,22,4]. These authors work with controlled mixtures of reconstituted Bangkok clay and cement slurry, formed and cured in the laboratory

Cement content on the mixture is specified by $A_{w}$, the ratio between cement weight and dry soil weight. It was observed that the mechanical behaviour of the mixture was mostly controlled by the ratio between current void ratio and cement content $\left(e_{0 t} / A_{w}\right)$. This mixing ratio accounts for the effects of initial clay water content, slurry water/cement ratio, slurry/clay mixing ratio and, because of using the current void ratio, curing time. Different combinations of these variables that result in the same mixture ratio $\left(e_{0 t} / A_{w}\right)$ show, approximately, the same mechanical response.

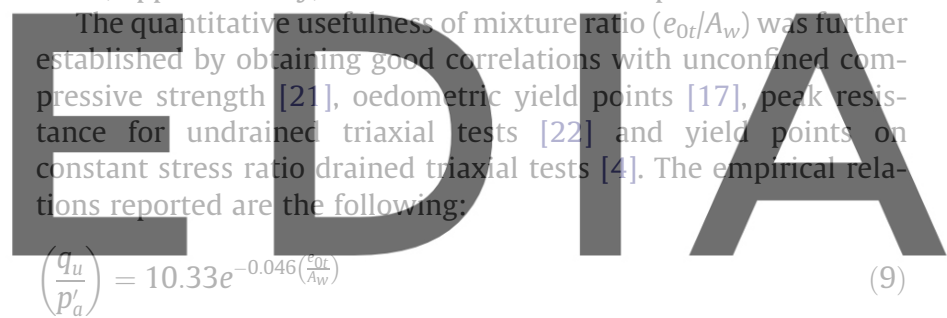

dowm.kadpthetakepstion without the watermark

$$
\begin{aligned}
& \left.\frac{q_{\text {peak }}}{p_{c}^{\prime}}=44.243 e^{-\left(\frac{p_{c}^{\prime}}{p_{a}^{\prime}} 0.0501\right.} \frac{e_{0 t}}{A_{w}}\right) \\
& p_{c}^{\prime}=0.49\left(\frac{e_{0 t}}{A_{w}}\right)^{2}-31.9\left(\frac{e_{0 t}}{A_{w}}\right)+733
\end{aligned}
$$

where $q_{u}$ represents the unconfined compression strength, $p_{a}^{\prime}$ is the atmospheric pressure, $\sigma_{v y}^{\prime}$ the oedometric yield stress, $q_{\text {peak }}$ the peak resistance for undrained triaxial tests and $p_{c}^{\prime}$ the intersection of the yield surface of the mixture and the isotropic axis. All stress variables in these relationships are expressed in $\mathrm{kPa}$.

Apart from this comprehensive set of observations, Lorenzo and Bergado [22] also report that $E_{50}$, the secant modulus (at $50 \% q_{u}$ ) in unconfined compression tests, can be expressed as

$E_{50}=\delta q_{u}$

for both laboratory samples and field cores of cement treated Bangkok clay. $\delta$ is a proportionality constant that ranges between 115 and 150 for the Bangkok clay database. This kind of linear relation between secant modulus and unconfined compressive strength has been previously reported for other cement-treated clays e.g. [27], with $\delta$ values between 50 and 300 being very common.

\section{Relating empirical observations and constitutive model}

The constitutive model described above relates 3 state variables through a set of equations involving 11 material parameters. On the other hand, the empirical relations (9)-(13) include up to nine different numerical coefficients. The objective of this section is to 
explore whether these two apparently disparate set of numbers can be related in a manner that eases the task of model calibration. This would represent a significant contribution towards the use of advanced models in practice.

In Eq. (12) we employed deliberately the symbol $p_{c}^{\prime}$ to highlight the direct connection between this empirical relation and the model variables. The particular expression employed in (12) has a minimum when the ratio $e_{0 t} / A_{w}$ is about 32 (Fig. 2). Such property seems unphysical, since the isotropic yield stress cannot increase indefinitely. To avoid this problem the same experimental data can be advantageously fitted, for instance, by the following expression:

$p_{c}^{\prime}=F\left(\frac{e_{0 t}}{A_{w}}\right)=k_{1} e^{-k_{2}\left(\frac{e_{0 t}}{A_{w}}\right)}+k_{3}$

where $k_{1}, k_{2}$ and $k_{3}$ are empirical constants. An example of this type of fit to the data reported by Bergado et al. [4] is given in Fig. 2. Expression (14) is still not fully satisfactory from the model viewpoint, because it predicts a constant isotropic yield stress when the cement content, $A_{w}$, tends to zero. But in that situation, according to the model, isotropic yield stress should recover the value of $p_{s}$. This argument suggests that an improved version of (14) should read $p_{c}^{\prime}=F\left(\frac{e_{0 t}}{A_{w}}\right)+p_{s}^{\prime}=k_{1} e^{-k_{2}\left(\frac{e_{0 t}}{A_{w}}\right)}+p_{s}^{\prime}$

Bergado et al. [4] provide separate values of $e_{0 t} / A_{w}$ and $e_{0 t}$ for their triaxial samples. Assuming that a $p_{0 t}^{\prime}$ of $10 \mathrm{kPa}$ is relevant at sample formation (laterally confined in a PVC mould) the relevant $p_{s}$ value can be estimated following parameters $N, \lambda, \kappa$ established as As illustrated in Fig. 3, a very good resulting from Eq. (15) and the ex 2 and $k_{2}=0.033$.

The role of the empirical function F is cructal for the approach here described. F links together a compositional measure, the ce-

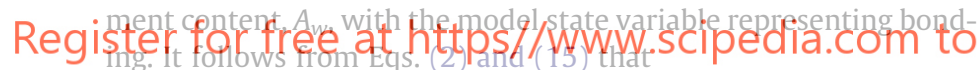

\section{$p_{s}^{\prime} b=F\left(e_{0 t} / A_{w}\right)$}

As explained before, initialization of $p_{s}^{\prime}$ requires knowledge of $\left(e_{0 t}, p_{O t}^{\prime}\right)$. Then, for a given cement content $A_{w}$, the state variable $b$, representing bonding in the model can be easily initialized.

However, if a large set of drained triaxial tests, (such as those reported by [4], is required to establish the empirical function $F$, the practicality of this approach might be questioned. A simpler

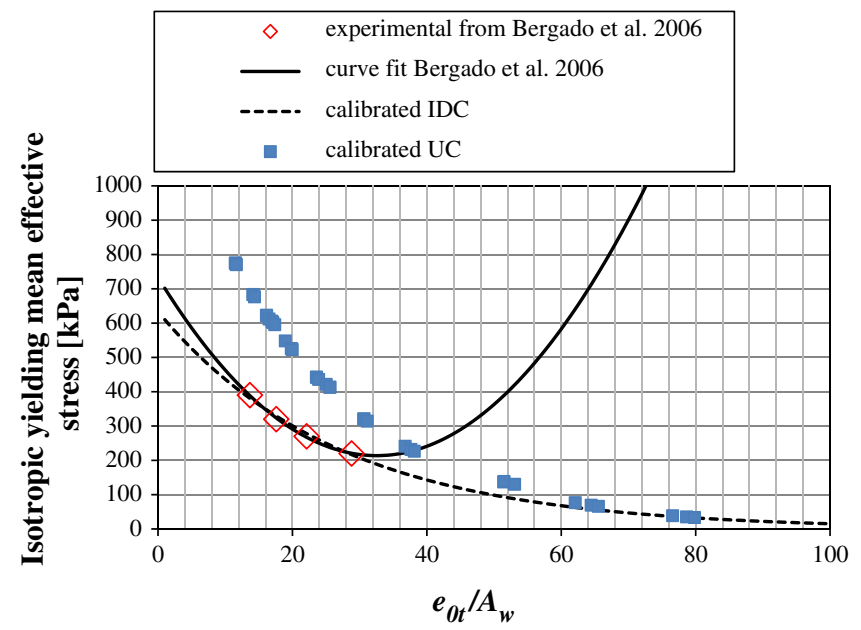

Fig. 2. Isotropic yielding of cemented Bangkok clay vs. mixture ratio.

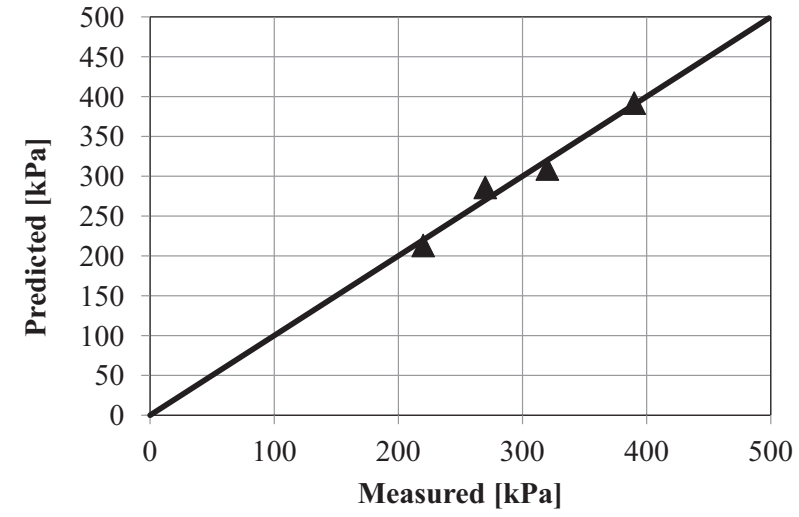

Fig. 3. Measured vs. predicted yield stress according to Eq. (15), with $k_{1}=525$, $k_{2}=0.031$.

means to establish $F$ is desirable and that can be obtained by considering unconfined compressive strength from the model viewpoint. Rearrangement of the yield surface expression (1) gives,

$$
q=M\left(p^{\prime}+p_{t}^{\prime}\right)\left(-\frac{1}{\ln r} \ln \frac{p^{\prime}+p_{t}^{\prime}}{p_{c}^{\prime}+p_{t}^{\prime}}\right)^{1 / n}
$$

Unconfined compression tests are carried out quickly and undrained behaviour can be assumed. For specimens close to satura-

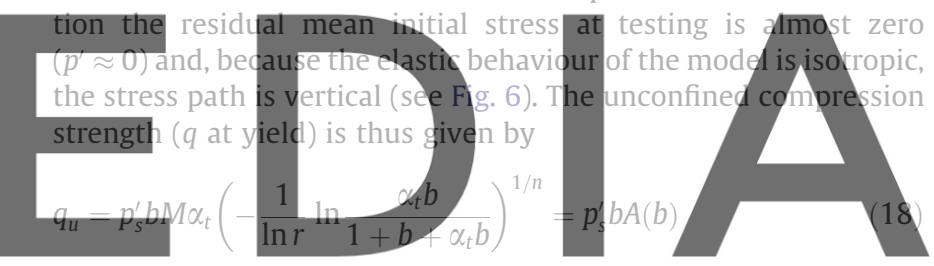

where $A(b)$ depends on the model parameters $\left(M, r, n, \alpha_{t}\right)$ and the download the version withouth the watermark $A=M \alpha_{t}\left(-\frac{1}{\ln r} \ln \frac{\alpha_{t} b}{1+b+\alpha_{t} b}\right)$

It turns out that, for the relevant range of $b$ values, $A$ is almost constant (for instance, Fig. 4 represents the case for Bangkok clay parameters shown later, and it can be seen that $A \approx 1$ for $b>1$ ). Using this fact and taking (16) into account

$q_{u}=A F\left(e_{0 t} / A_{w}\right)$

If we now substitute Eq. (8) in Eq. (14) we obtain an expression that is already very close to the empirical relation between unconfined compression strength and $e_{0 t} / A_{w}$ ratio.

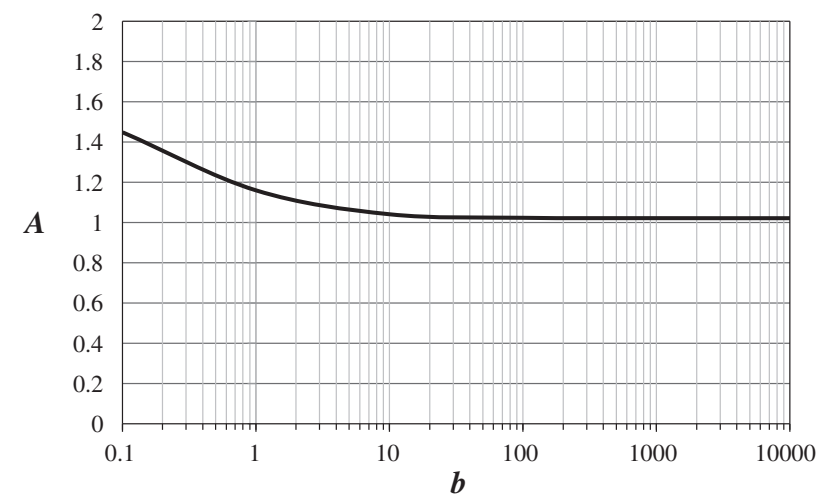

Fig. 4. Graphic representation of Eq. (15). 
Table 2

Calibration of function $F$ using isotropic yield data and unconfined compressive strength.

\begin{tabular}{|c|c|c|c|}
\hline \multicolumn{2}{|l|}{ IYL } & \multicolumn{2}{|l|}{ UCS } \\
\hline$k_{1}$ & $k_{2}$ & $k_{1}$ & $k_{2}$ \\
\hline 543 & 0.033 & 1025 & 0.046 \\
\hline
\end{tabular}
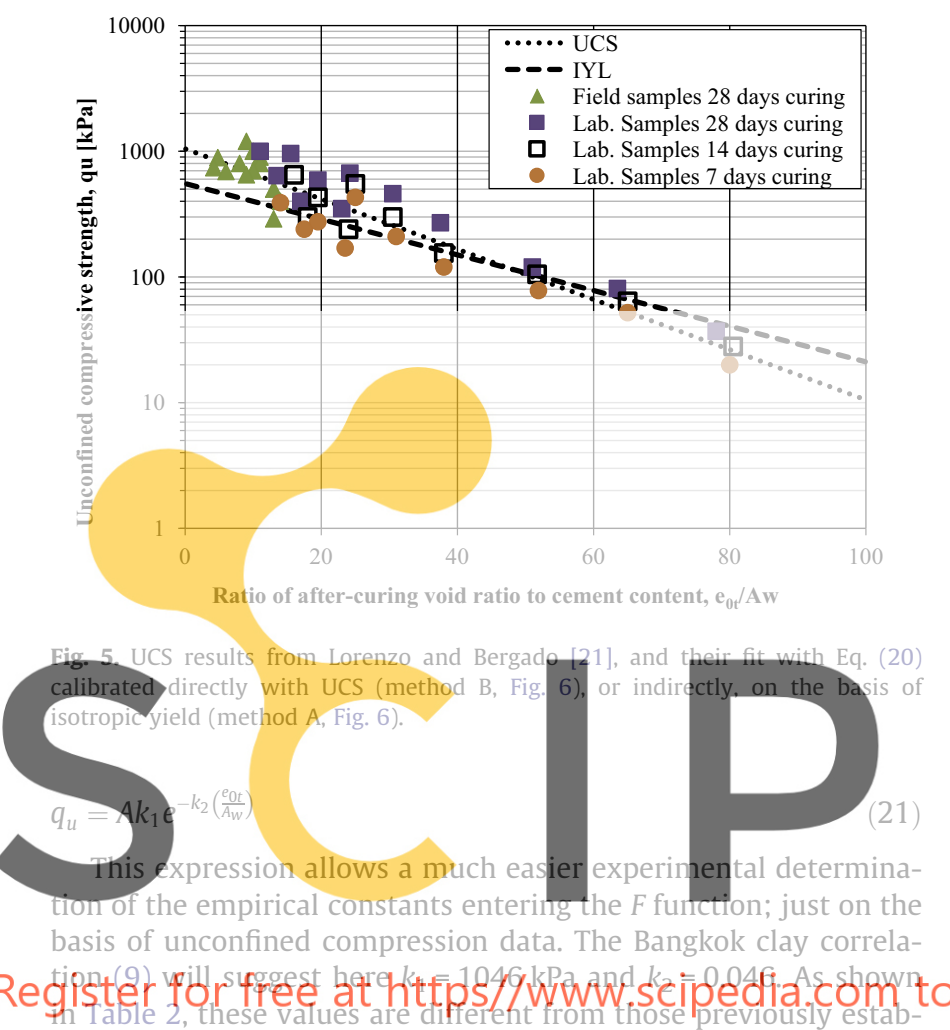

lished on the basis of isotropic yield points. On the other hand, if the values calibrated from isotropic yield are used to evaluate Eq. (21), the comparison with the data, (Fig. 5) is less favourable than that obtained using the isotropic yield based calibration. Since the UCS database was larger and wider in scope (in the range of mixture ratios, $e_{0 t} / A_{w}$, that it covered) it is perhaps preferable to give more credence here to the UCS-based calibration of $F$. The correctness of this assumption will be checked in the next section, where oedometric and triaxial undrained compression results will be simulated. Thus the validation would take place alongside different stress paths (Fig. 6) than those involved in the calibration of $F$.

Before proceeding to that, however, it is worth presenting one further analytical development, to explain the empirical expression (13) relating secant modulus, $E_{50}$, and $q_{u}$. To do so, we should first use (7) and the relation between Young's and elastic bulk moduli, to write

$$
E_{c}=3(1-2 v) K_{c}=3(1-2 v) \frac{(1+e) p^{\prime}}{\kappa}\left(1+\sqrt{\frac{p_{s} b}{p^{\prime}}}\right)
$$

At the point where $E_{50}$ is defined, the mean stress in the sample is $p^{\prime}=q_{u} / 6$. Also, Eq. (18) above, shows that $p_{s}^{\prime} b=q_{u} / A$, It follows then that

$E_{50}=\frac{(1-2 v)}{2 \kappa}\left(1+\sqrt{\frac{6}{A}}\right)(1+e) q_{u}$

Which has the same form of the empirical expression, (13), and suggest that the proportionality constant between $E_{50}$ and $q_{u}$ would be given by

$\delta=\frac{(1-2 v)}{2 \kappa}\left(1+\sqrt{\frac{\sigma}{A}}\right)(1+e)$

Interestingly, it will appear that the stiffness/strength ratio is only lightly dependent on the amount of cement in the mixture (through $A$ ) whereas is directly proportional to the specific volume of the cemented material. It has been therefore established that it is possible to make the advanced constitutive model consistent with relationships of a purely empirical nature.
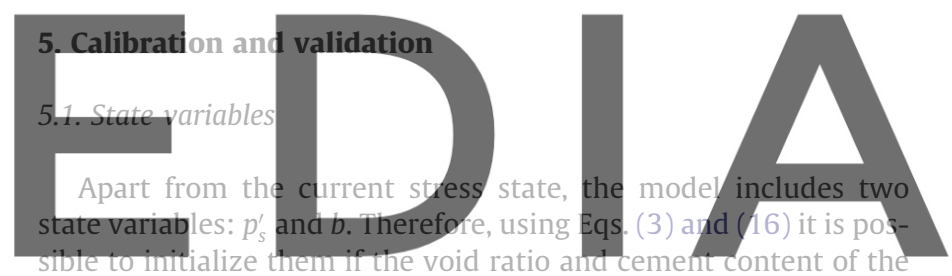

mixture is known. For all the tests simulated below the data on ce-

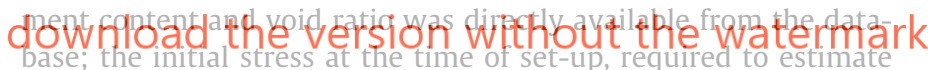
$p_{s}^{\prime}$ was assumed equal to $10 \mathrm{kPa}$ in all cases. The constants employed in the empirical function $F$ are those obtained from the calibration using UCS data.

\subsection{Parameters of the reference material}

There are eight parameters in the model that describe the mechanical response of the reference material (Table 1 ). Reconstituted Bangkok clay is assumed here as reference for the cementtreated Bangkok clay. As many other soft clays, Bangkok clay is naturally endowed with a certain amount of structure [33], and therefore its response is not always representative of that of the same reconstituted material. This made difficult the ideal approach

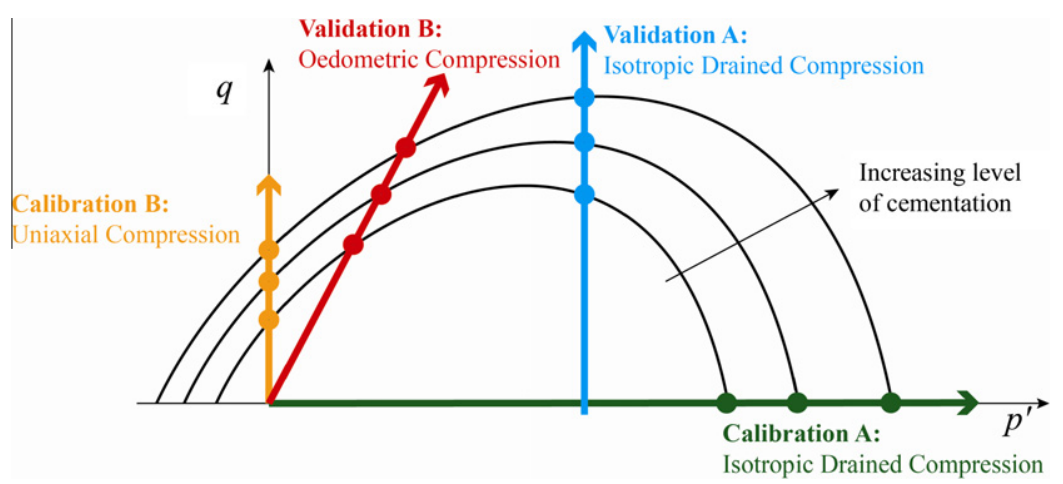

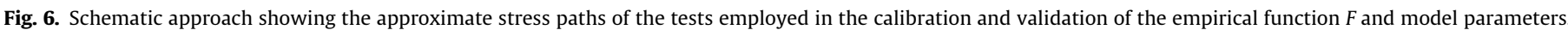


to the calibration of these parameters, which is by examining tests on the reference material only. Only for the critical state friction angle such approach was possible (with data from [19].

Alternative approaches were then employed. The classical Burland [6] correlation between plasticity and reconstituted compressibility was used to obtain estimates of the relevant parameters $(\lambda, N)$. The degree of non-associativeness (controlled by parameter $m$ ) was established by forcing the stress-paths of simulated oedometers on reconstituted materials to abide with the Jaky $K_{0}$ condition. The shape of the yield surface (and hence parameters $n$ and $r$ ), was inferred from observations of its shape for the improved material [4]. This last procedure is consistent with the model assumption that the shape of the yield surface is not altered by cementation. Finally, the elastic parameters were estimated as $\kappa \approx 0.03$ and $v \approx 0.2$. The first guess is consistent with

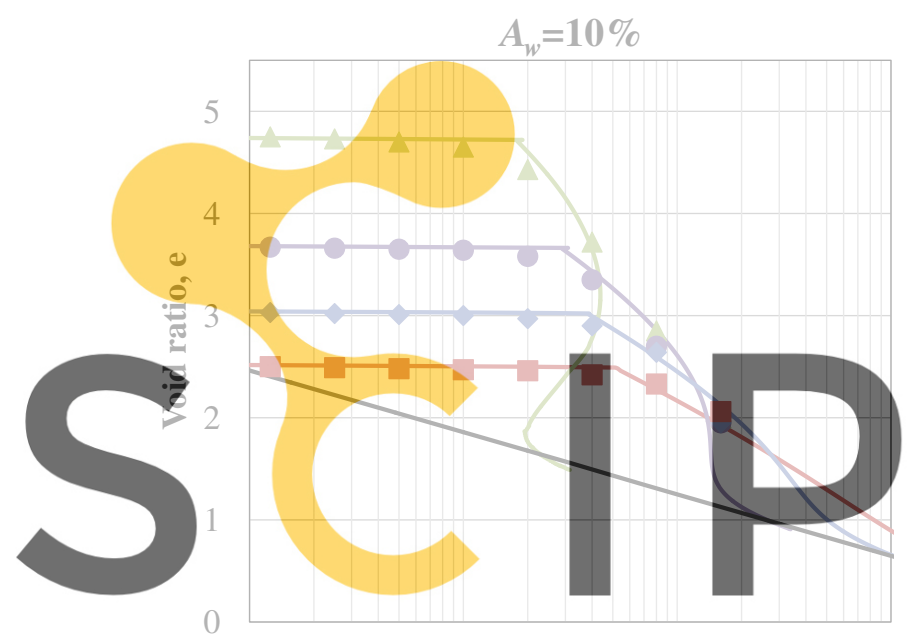

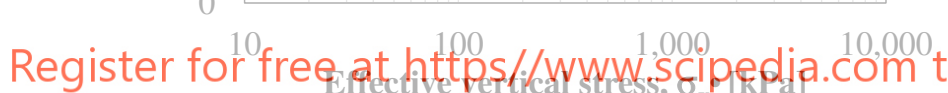

Fig. 7. Void ratio vs. effective vertical stress on incremental loading oedometric tests. Data points: test results [21]. Continuous line: model simulations.

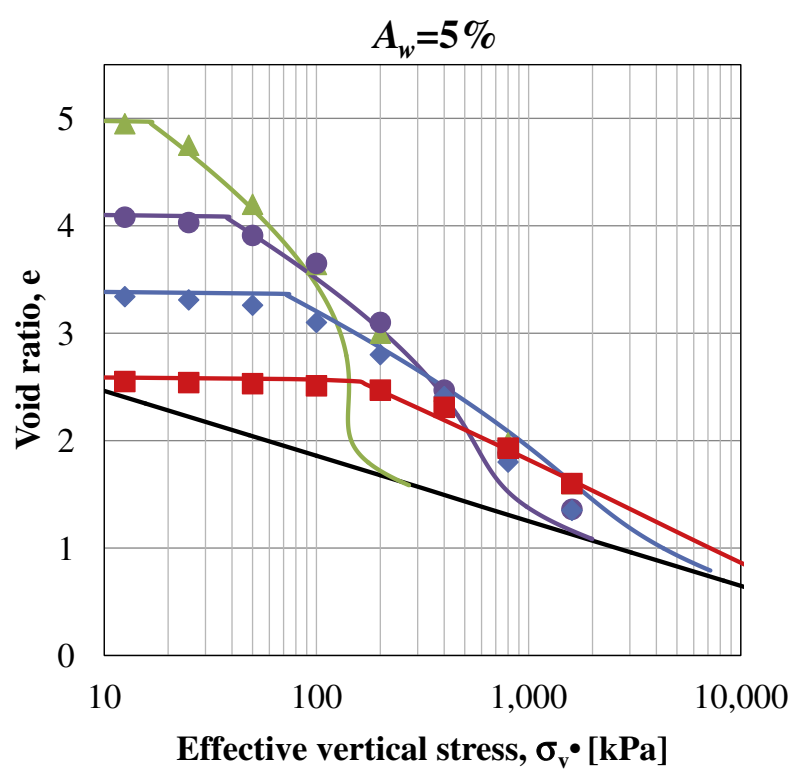

Fig. 8. Void ratio vs. effective vertical stress on incremental loading oedometric tests. Data points: test results [21]. Continuous line: model simulations. a ratio $\Lambda=1-\kappa / \lambda$ of 0.89 , which is within the typical range for clays. The second estimate stems from relation (24) taking into account the range of $\delta$ reported by Lorenzo and Bergado [22]. The resulting parameter set is collected in Table 1 . More details about parameter calibration are given by Ciantia [9].

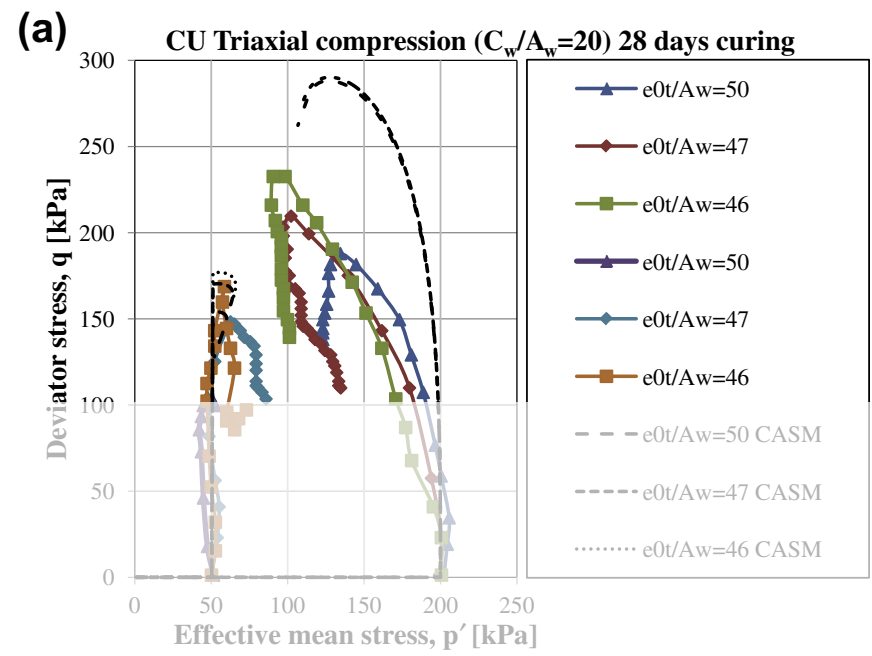

(b) CU Triaxial compression $\left(\mathrm{C}_{\mathrm{w}} / \mathrm{A}_{\mathrm{w}}=15\right) 28$ days curing

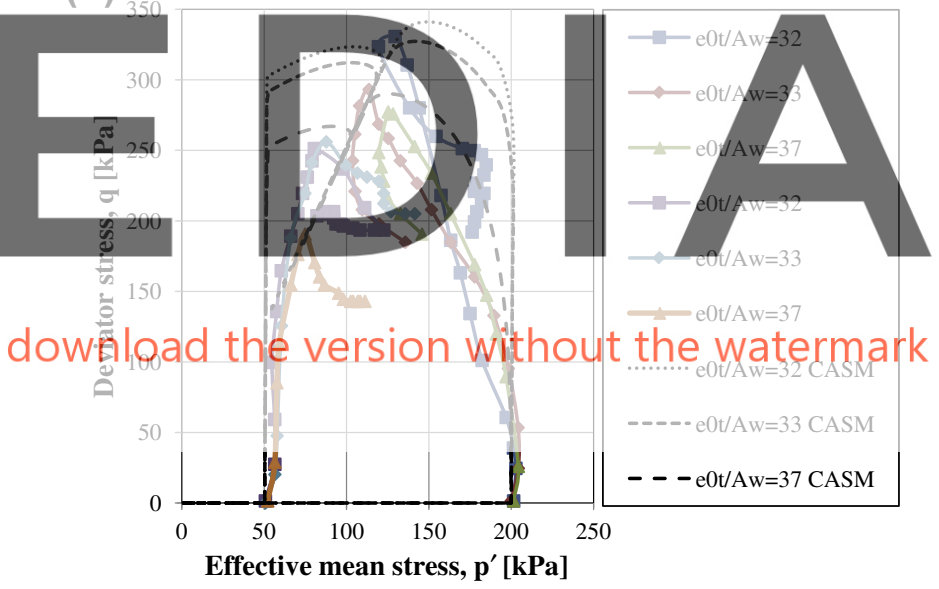

(c) CU Triaxial compression $\left(\mathrm{C}_{\mathrm{w}} / \mathrm{A}_{\mathrm{w}}=10\right) 28$ days curing

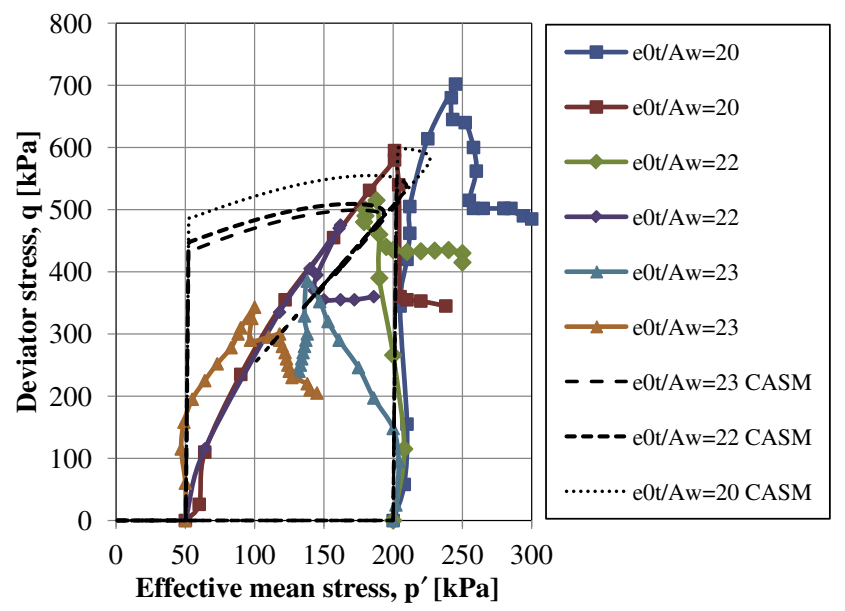

Fig. 9. Stress paths on undrained triaxial compression of isotropically consolidated specimens (TXCIU tests) for variable mixture ratios (a) $e_{i} / A_{w}=46-50$, (b) $e_{i} / A_{w}=32-$ 37 and (c) $e_{i} / A_{w}=20-23$. Lines with symbols: experimental results [22]. Dotted lines: model predictions. 


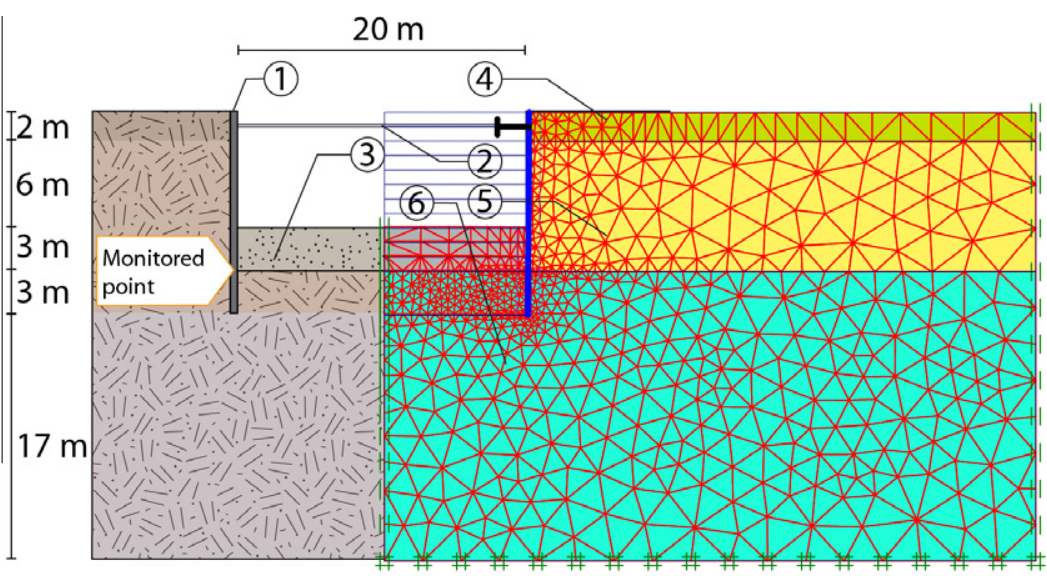

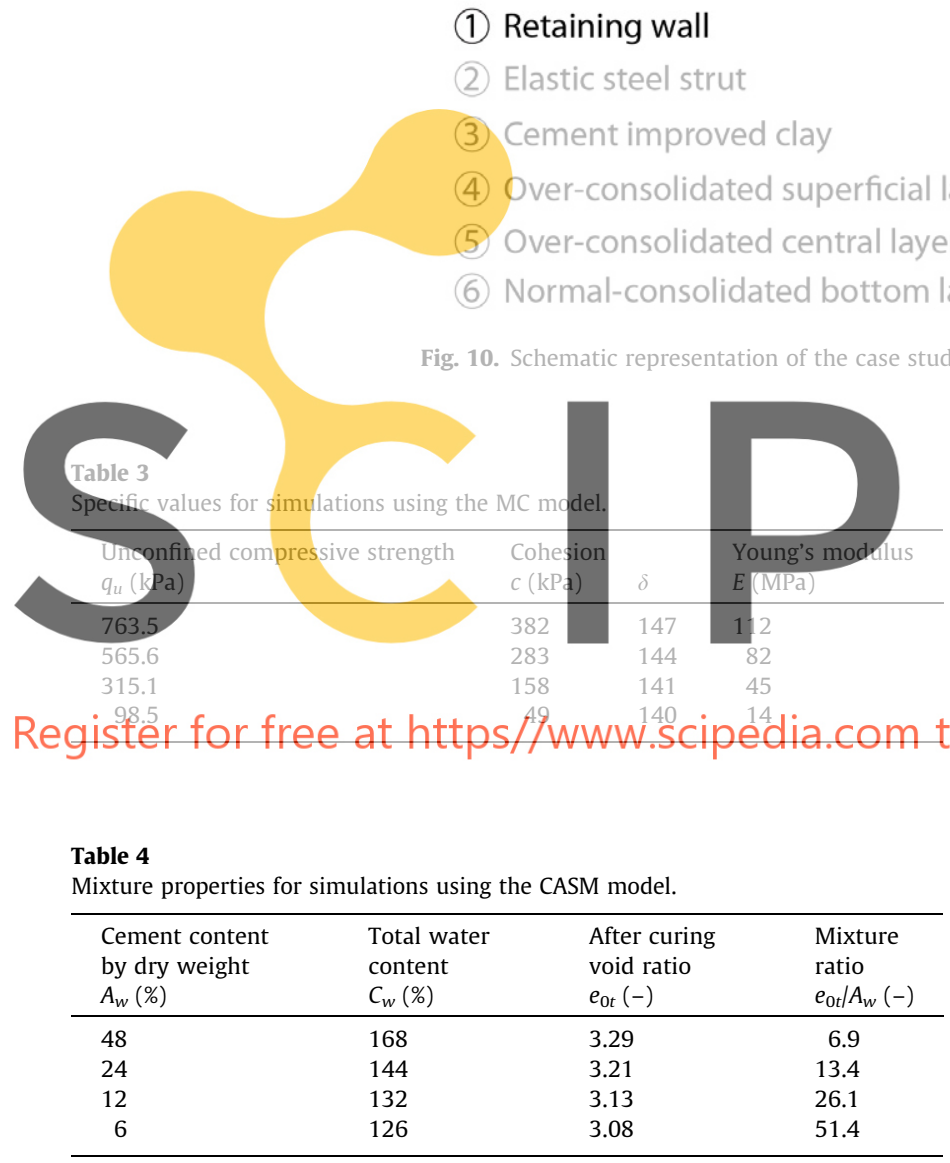

\subsection{Parameters of the cemented material}

There are three parameters specific to the behaviour of the cemented material: the tension intercept parameter, $\alpha_{t}$ and the degradation rate parameters, $h_{1}$ and $h_{2}$ (6). The value of $\alpha_{t}$ was estimated as 0.5 based on the yield surfaces reported by Bergado et al. [4]. The ratio $h_{1} / h_{2}$ was assumed equal to 1 , following results for naturally cemented clay by Callisto and Rampello [7]. To evaluate the remaining parameter, $h_{1}$, simulations of oedometer tests for mixtures with a fixed cement content $\left(A_{w}=10 \%\right.$, Fig. 7$)$ were performed.

It appeared that a better fit was achieved if the $h_{1}$ parameter was made slightly dependent on the initial bonding of the material, $b_{0}$. The following dependency was observed

$h_{1}=0.625 \ln \left(b_{0}+1\right)$

\section{General Options: \\ Model: Plane Strain \\ Elements: 15-Noded \\ Mesh: \\ $N^{\circ}$ elements: 1564 \\ $\mathrm{N}^{\circ}$ nodes: 13125}

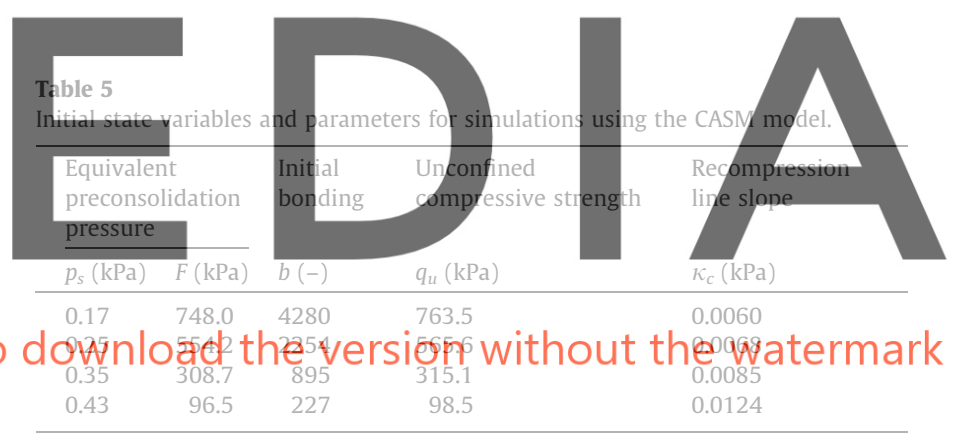

It is worth noting that the simulations of the oedometric tests are made with displacement control (constant rate of strain tests); the data, however, was obtained using load control (incremental loading procedure). The simulations show a snap-back pattern in the oedometric curve, particularly clear for the sample with highest porosity. This phenomenon would not be observed in a loadcontrolled test, where a material instability in the form of a compaction band would instead appear. The appearance of compaction instabilities in oedometric loading of bonded soils and soft rocks is discussed and documented elsewhere $[2,8]$.

\subsection{Validation examples}

With the parameters and state variable initialization criteria that have been just described, numerical simulations of several test results were used to validate the approach. First, different sets of oedometric results (corresponding to $A_{w}=5 \%$ and $A_{w}=15 \%$ ) reported by Lorenzo and Bergado [21] were simulated. Example results are shown in Fig. 8. Further validation was obtained against a set of undrained triaxial tests reported by Lorenzo and Bergado [22]. An example of the results obtained is shown in Fig. 9.

The degree of approximation obtained with the element test simulations was deemed satisfactory enough so that the next step (simulations at the structure scale) could be attempted with meaningful results. Note that the softening response evident in 
some stress paths would not be replicated by a Mohr-Coulomb model. More details of the element test simulations are provided in Ciantia [9].

\section{Application to a structure-scale problem}

\subsection{Description of the case}

In practice, jet grout slabs are not common in Bangkok, possibly because deep excavations penetrate below the clay level into stiffer layers (Phienwej et al., [26]. A hypothetical case (Fig. 10) was then built into a finite element model with the specific purpose of exploring the sensitivity of the analysis to the material characterization of the treated soil.

The developed case study involves three layers of clay, with normally consolidated clay below excavation level, an over-consolidated layer on the surface and an intermediate medium-consolidated layer (Fig. 10) at excavation level. All these clay layers were modelled using the CASM model. The model parameters in all layers were those previously established for the reconstituted Bangkok clay (Table 1). The stress state was initialized with the $K_{0}-$ OCR relationship of Mayne and Kulhawy [23].

A thick $(1 \mathrm{~m})$ concrete $(E=30 \mathrm{MPa})$ retaining wall was supported at $0.5 \mathrm{~m}$ below its top by a rigid strut $(400 \mathrm{kN} / \mathrm{m} / \mathrm{m})$ and at its bottom by a $3 \mathrm{~m}$ thick layer of cement treated clay. The excavation maximum depth was set at $8 \mathrm{~m}$. The excavation process is simulated as a sequence of uniform excavation steps, of $1 \mathrm{~m}$ depth each.
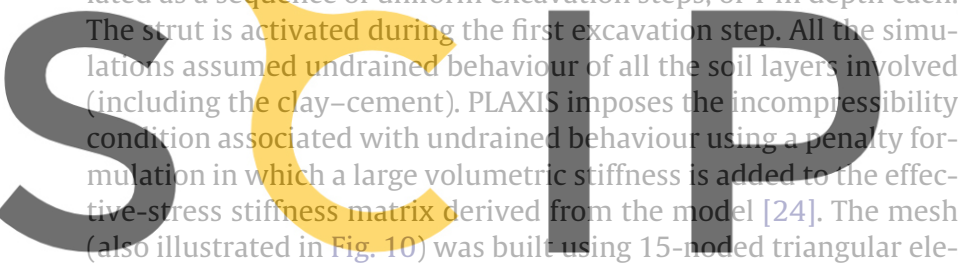

ments with 12 Gauss points (stress points) in each element.

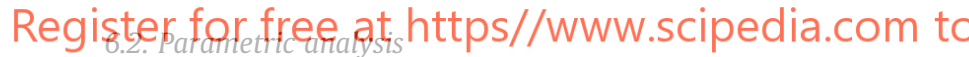

A parallel parametric analysis, concerning the behaviour of the clay-cement treated soil, was performed employing two constitutive models. A linear elastic-perfectly plastic model with Mohr-Coulomb yield (MC) and the model described in the previous sections (bonded CASM). The parameter is the unconfined compressive strength (UCS, $q_{u}$ ) of the clay-cement.
When the clay-cement behaviour was represented using the MC model the only state variable of the material is stress. The initial stress of the slab is assumed isotropic with value equal to the initial vertical stress. Four values of unconfined compressive strength were chosen for the parametric analysis (Table 3). Friction and dilatancy were neglected and strength was given by the cohesion which was equal to half the UCS. Young's modulus was taken to be directly proportional to the UCS, according to Eq. (13). For each case, the constant of proportionality was evaluated through Eq. (24). The resulting values (Table 3 ) are in the range 140-150, in agreement with the Bangkok clay data reported by Lorenzo and Bergado [22].

When the clay-cement mixture was modelled using the bonded CASM model a larger number of state variables required initialization. Clay-cement mixtures with the same UCS as in the previous case were the target. To achieve that it was first necessary to make some assumptions about the initial clay water content $(120 \%$ for soft Bangkok clay, [3], the water/cement (W/C) ratio in the slurry mixed with the clay (chosen as 1 ) and the curing time before the mixture attained the specified UCS ( 90 days, to allow for a fast but realistic construction schedule). Then, four values of cement content $A_{w}$ were specified to attain the target UCS. Of all the mixture cement contents of Table 4, only the highest one (48\%) is characteristic of jet-grouted mixtures, whereas the others are within the typical range observed in deep soil mixing treatments.

The initial void ratio for the simulation is the after curing void ratio, $e_{0 t}$. Following Lorenzo and Bergado [21], $e_{0 t}$ can be deduced

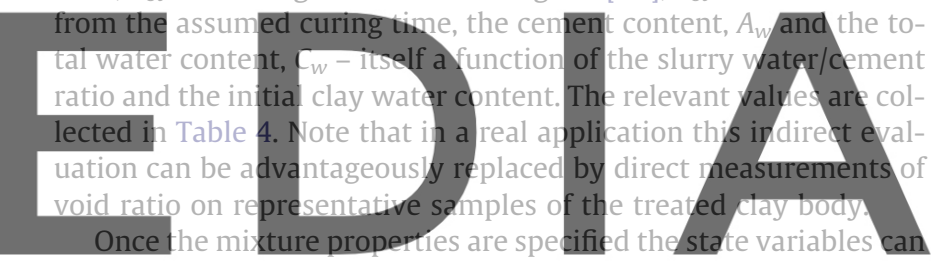
be initialized using the procedure described above. The results obtained for the cases here analysed are shown in Table 5. The

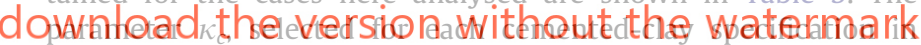
agreement with Eq. (8), is also indicated in the same table.

\subsection{Simulation results}

Only a few selected simulation results are presented here. In Fig. 11 the movements in a point located at the contact between the soil-cement slab (Fig. 10) and the retaining wall are

TRESCA

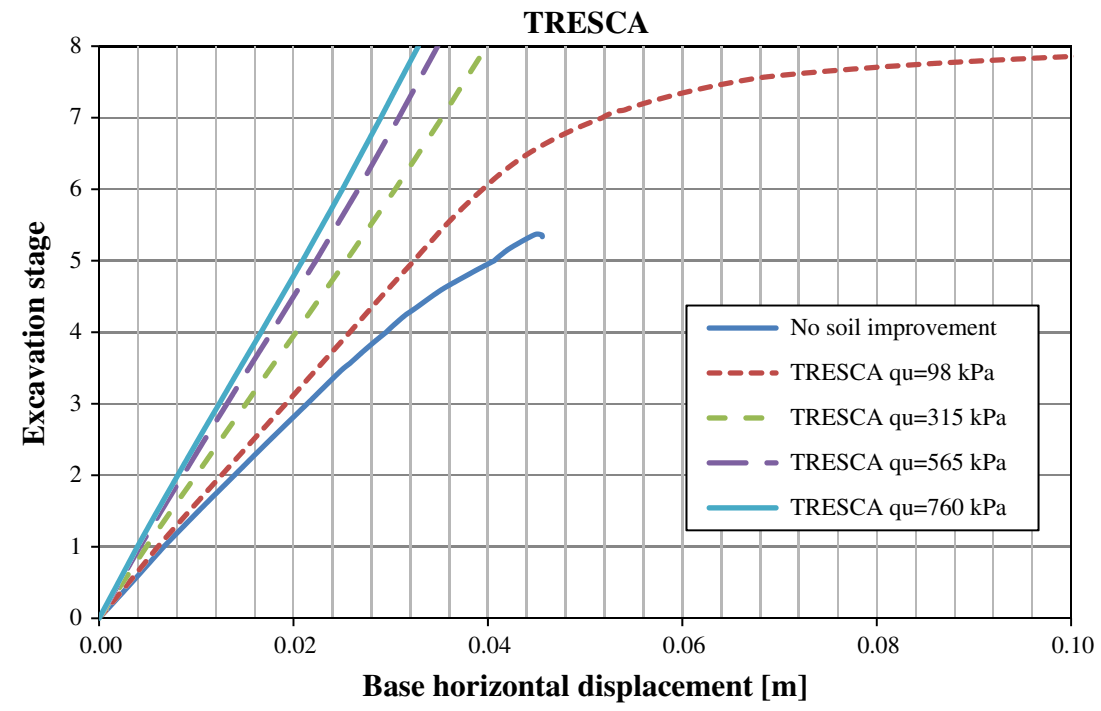

Fig. 11. Horizontal displacement at the monitoring point vs. excavation stage. Jet-grout slab modelled using MC. 


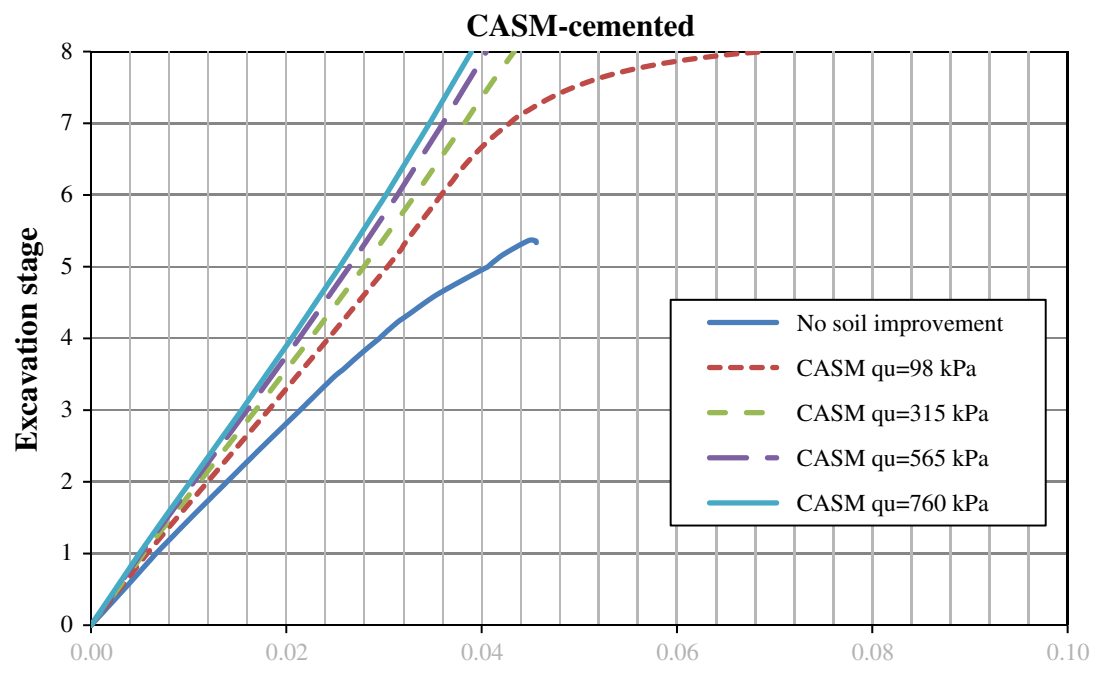

Base horizontal displacement [m]

Fig. 12. Horizontal displacement at the monitoring point vs. excavation stage. Jet-grout slab modelled using CASM-cemented.

represented for the four cases computed using the MC model, against the excavation stage. As a reference the results obtained in a simulation where no slab of soil-cement is present are also included in the graph. Fig. 12 represents the same results but now for the cases computed using the bonded CASM model.
The excavation is unstable without soil treatment. The model
a numesenting the excavation with no slab of clay-cement exhibited
case with the lightest soil treatment, $1 . e$. with the smallest apount
of cement in the clay-cement slab ( $A_{w}=6 \%$; UCS $\left.=110 \mathrm{kPa}\right)$ there
was a narked divergence in the response of the model, according to which constitutive model was employed to represent the soilcement. When the slab was modelled using bonded-CASM there

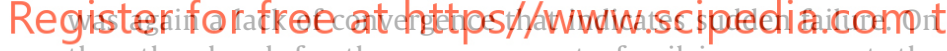
the other hand, for the same amount of soil improvement, the MC model converged, exhibiting a more ductile structural response, characterized by large dispiacements.

For the cases with a higher degree of soil improvement both constitutive models resulted in almost the same, rather stiff,

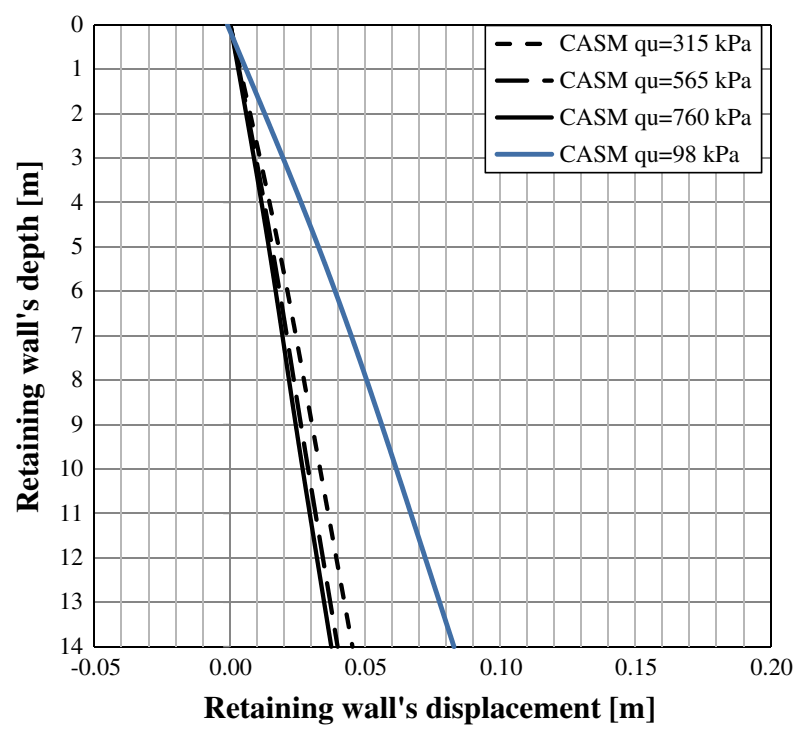

Fig. 13. Horizontal displacement of the retaining wall vs. depth. Jet-grout slab modelled using CASM.

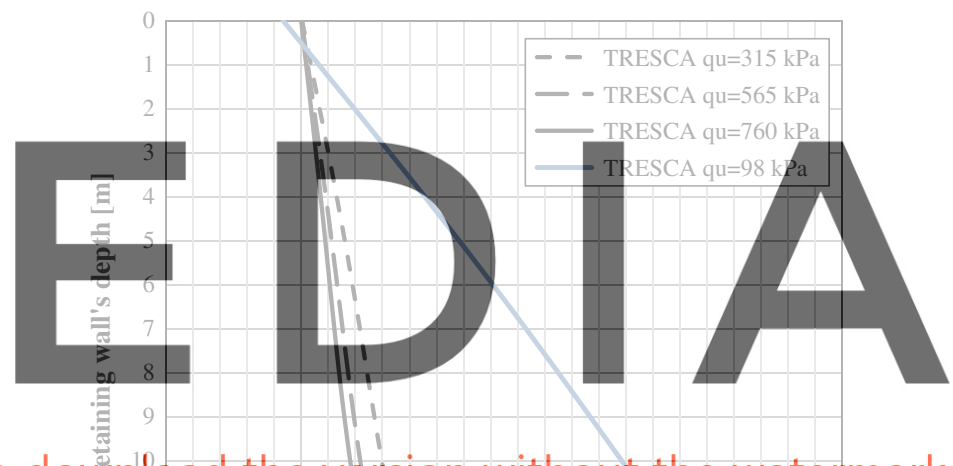

dow whload the version without the watermark

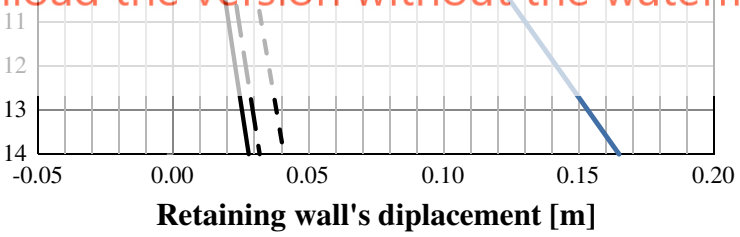

Fig. 14. Horizontal displacement of the retaining wall vs. depth. Jet-grout slab modelled using MC.

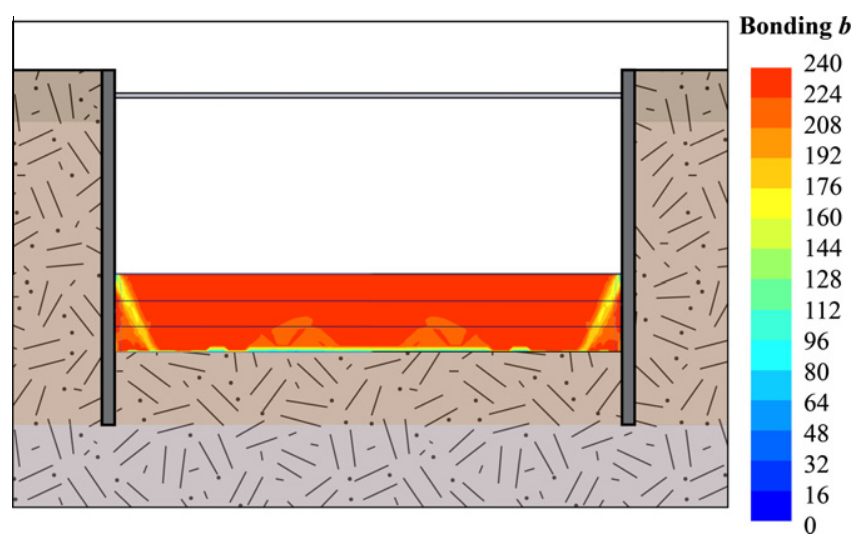

Fig. 15. Bonding variable " $b$ " values at the final stage of the CASM simulation for $q_{u}=98 \mathrm{kPa}$. 
response. In these cases the behaviour of the slab is almost elastic and the similar response is due to the deliberate matching of stiffness obtained through relation (24).

Similar observations can be made if the movement of the whole wall is considered (Figs. 13 and 14). For all cases the improved slab stiffness is always well below that of the head strut support, and an inverted cantilevered profile develops. Again, there is a marked difference between the cases where elastic behaviour predominates in the slab, to the one where plasticity takes place. The small wall motions of the first case are highly increased, particularly for the MC case. It has been already mentioned, in this respect, that for less cemented case the bonded-CASM simulation did not converge. An image just before collapse illustrates a localized pattern of debonding, which concentrates in a compression band close to the wall (Fig. 15).

\section{Conclusions}

The use of bonded elasto-plastic models seems to reproduce well the behaviour shown by cement-improved clay in the laboratory. This paper shows that a direct relation can be obtained between basic model variables (bonding, equivalent preconsolidation) and simple experimental measures (unconfined compressive strength, porosity). This greatly simplifies the application of this type of models in boundary value problems, where the predicted structural response can be also significantly affected.

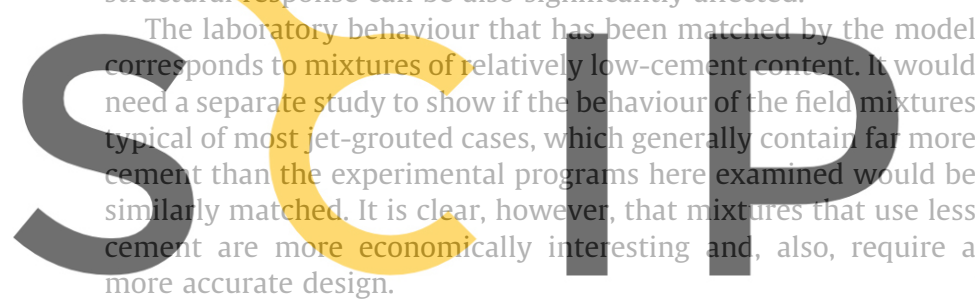

From the results presented in this paper it can be already con-

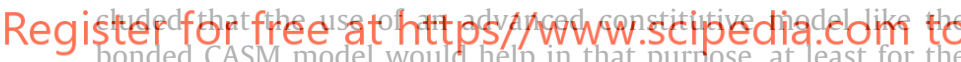
case of clay cement slabs supporting retaining walls. For the same UCS, a more clear indication of the vicinity of failure would be given by an analysis using bonded CASM than MC. These results also suggest that caution should be exercised if the simplified MC approach is used as a base for design or for establishing safety criteria based on monitoring observations.

The particular formulation here employed for the bonded elastoplastic model is perhaps less important than the calibration approach that has been exemplified. This approach has several steps. First some knowledge of the basic mechanical properties of the reference material (the remoulded soil being treated) is required. This might be obtained from standard tests on remoulded - hence easily obtainable - samples. Secondly an empirical relation between mixture ratio and UCS does provide the link between easily obtained treatment parameters and a nuanced representation of the treated soil mechanical response via the basic state variables of the model. Finally, for a more refined representation of the treated soil behaviour, some tests - for instance oedometer - on cemented samples would capture the parameters controlling the most specific aspects of cemented soil behaviour, such as bond degradation rate. This stepwise approach seems well adapted to fit within the staged design approach that is usually applied in large soil improvement projects.

\section{Acknowledgements}

This work was made possible through an Integrated Action Italy-Spain (ES: HI2008-0039; IT: A.F. 2009, $\mathrm{n}^{\circ} 18$ ) Dr. N.A.
Gonzalez, from UPC, provided the Plaxis subroutine coding the cemented CASM model and solved many numerical doubts. The support of the Spanish Ministry of Science through research Grants BIA2008-06537 and BIA2011-27217 is also gratefully acknowledged.

\section{References}

[1] Arroyo M, González N, Butlanska J, Gens A, Dalton C. SBPM testing in Bothkennar clay: structure effects. In: Huang Mayne, editor. Geotechnical and geophysical site characterization. London: Taylor \& Francis Group; 2008. p. 456-62.

[2] Arroyo M, Castellanza R, Nova R. Compaction bands and oedometric testing in cemented soils. Soils Found 2005;45(2):181-95.

[3] Balasubramaniam AS, Hwang ZM, Uddin W, Chaudhry AR, Li YG. Critical state parameters and peak stress envelopes for Bangkok clays. Quart J Eng Geol Hydrogeol 1978;11:219-32.

[4] Bergado DT, Taechakumthorn C, Lorenzo GA, Abuel-Naga HM. Stress deformation behaviour under anisotropic drained triaxial consolidation of cement treated soft Bankok clay. Soils Found 2006;46(5):629-37.

[5] Brinkgreve RBI, Broere WI, Waterman D. PIAXIS. Finite element code for soil and rock analyses, users manual. The Netherlands; 2006.

[6] Burland JB. On the compressibility and shear strength of natural clays. Geotechnique 1990;40(33):329-78.

7] Callisto L, Rampello S. An interpretation of structural degradation for three natural clays. Can Geotech J 2004;41:392-407.

[8] Castellanza R, Gerolymatou E, Nova R. Experimental Observations and Modelling of compaction bands in oedometric tests on high porosity rocks. Strain 2009:45:410-23.

9] Ciantia MO. Modellazione del comportamento meccanico di terreni fini trattati con cemento, Tesi di Laurea, Facolta di Ingegnieria, Politecnico di Milano; 2009.

[10] Di Prisco C, Matiotti R, Nova R. A mathematical model of grouted sand allowing for strength degradation. Numer Model Geomech 1992:25-35.

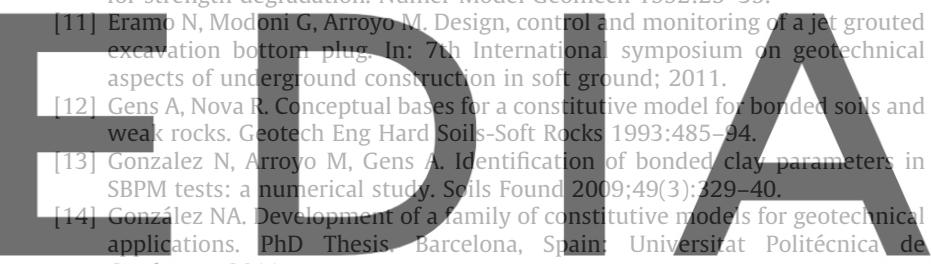
Catalunya: 2011.

[15] Ho CE, Hu S, Numerical analysis of jet grout elements for braced excavation in

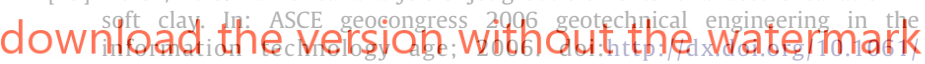
40803(187)260.

[16] Horpibulsuk S, Liu MD, Liyaparathina DS, e Suebsuk J. Behaviour of cemented clay simulated via the theoretical framework of the structured cam clay model. Comput Geotech 2010;37:1-9.

[17] Horpibulsuk S, Bergado DT, Lorenzo GA. Compressibility of cement-admixed clays at high water content. Geotechnique 2004;53(2):151-4.

[18] JJGA (Japan Jet Grout Association). Jet Grouting Technology (JSG method, Column Jet Grout method) technical information, 13th ed. (October 2005). Unofficial translation by T. Inui, K. Soga, H. Ji \& Y. Ando; 2005.

[19] Kamei T, Tanaka M, Hayashi S. Comparison of shear characteristics of undisturbed and remoulded Bangkok clay. Mem Fac Sci Eng Shimane Univ 2004;38:1-7.

[20] Lagioia R, Nova R. An experimental and theoretical study of the behaviour of a calcarenite in triaxial compression. Géotechnique 1995;45(4):633-48.

[21] Lorenzo GA, Bergado DT. Fundamental parameters of cement-admixed clay new approach. J Geotech Geoenviron Eng ASCE 2004:1042-50.

[22] Lorenzo GA, Bergado DT. Fundamental characteristics of cement-admixed clay in deep mixing. J Mater Civ Eng ASCE 2006:161-74.

[23] Mayne PW, Kulhawy FH. Ko-OCR relationships in soil. J Geotech Eng Div ASCE 1982;108(GT6):851-72.

[24] Naylor DJ, Pande GN, Simpson B, Tabb R. Finite elements in geotechnical engineering. Swansea, UK: Pineridge Press; 1981.

[25] O'Rourke TD, McGinn AJ. Lessons learned for ground movements and soil stabilization from the Boston Central Artery. ASCE J Geotech Geoenviron Eng 2006;132(8):966-89.

[26] Phienwej N, Surarak Ch, Cai H, Suwansawat S, Guan H, Balasubramaniam A. Combined cut and cover and new Austrian tunnelling methods for MRT station in Bangkok sub-Soils. In:17th International conference on soil mechanics and geotechnical engineering. Proceedings of the international conference on soil mechanics and geotechnical engineering, 2009-10-05, 2009-10-10, Alexandria, Egypt; 2009.

[27] Porbaha A, Shibuya S, Kishida T. State of the art in deep mixing technology: Part III: Geomaterial characterization. Ground Improve 2000;3:91-110.

[28] Rios S. A general framework for the geomechanical characterization of artificially cemented soil, PhD thesis. Facultade de Engenharia, Universidade do Porto; 2011.

[29] Rouainia M, Wood DM. A kinematic hardening constitutive model for natural clays with loss of structure. Géotechnique 2000;50(2):153-64. 
[30] Sheng D, Sloan SW, Yu HS. Aspects of finite element implementation of critical state models. Comput Mech 2000;26:185-96.

[31] Sloan SW, Abbo AJ, Sheng D. Refined explicit integration of elasto-plastic models with automatic error control. Eng Comput 2001;18:121-154l.

[32] Shirlaw JN. Jet grouting soft clays for tunnelling and deep excavations - design and construction issues. In: Johnsen, Byle, Bruce, editors. Grouting and ground treatment: proceedings of the third international conference, February 10-12, 2003, New Orleans, Louisiana, ASCE; 2003.
[33] Shibuya S, Tamrakar SB. Engineering properties of Bangkok clay. In: Tan et al. editors. Characterisation and engineering properties of natural soils. Lisse: Sweets \& Zeitlinger; 2003. p. 645-92.

[34] Yu HS. CASM: a unified state parameter model for clay and sand. Int J Numer Anal Method Geomech 1998;22:621-53.

[35] Yu HS, Tan SM, Schnaid F. A critical state framework for modelling bonded geomaterials. Geomech Geoeng 2007;2(1):61-74. 